\title{
Multi Slot Uwb Antennas to Minimize the Interferences from Wlan \& X-Band Applications
}

\author{
S.SaiDivya ${ }^{1}$, N.RajaSekhar ${ }^{2}$, P.Devi $^{3}$, T.VinodhKumar $^{4}$, U.ChandraMouli ${ }^{5}$ \\ Department of Electronics and Communication Engineering, LIET, Jonnada, JNTUK, India
}

\begin{abstract}
In this paper designs of different UWB patch antennas with two rejected bands are given. The reference antenna consists of a rectangular patch etched on FR4-epoxy substrate with $50 \Omega$ feed line and relative permittivity 4.4.. The simulated bandwidth with return loss $(R L) \geq 10 \mathrm{~dB}$ is $3.42-11.7 \mathrm{GHz}$. The rejected bands here are the WLAN and X-bands, achieved by inserting slots in the patch and the feed. The simulation results of the antennas indicate higher gain at the pass bands while a sharp drop at the rejected bands is seen. The second (reference) antenna consists of a hexagonal patch etched on FR4- epoxy substrate with $50 \Omega$ feed line and relative permittivity 4.4,shows better return loss and rejection of the bands. The high frequency structure simulator (HFSS) is used to design and simulate the antennas behaviour over the different frequency ranges. Measurements confirm the antenna characteristic as predicted in the simulation with a slight shift in frequencies.
\end{abstract}

Keywords: MultiSlot, UWB, Patch, Band Rejection, HFSS.

\section{Introduction}

In this era, antennas are an essential part of any wireless communication system. With the technological advancements, antennas are playing even a bigger role. One of the rising interests is the use of antennas in UWB systems with high capacity communication links. In 2002, the federal communication commission (FCC) regulated the use of the 3.1-10.6 GHz band for commercial UWB applications. Due to the extremely wide operating bandwidth, it may possibly interfere with other existing electronic systems during the implementation of the UWB radio system. The UWB has been considered as one of the most promising wireless technology for transmission of signal at very high data rate, Low power consumption and low cost of hardware. In UWB communication systems, one of key issues is the design of a compact antenna while providing wideband characteristic over the whole operating band. Consequently, number of Antennas with different geometries has been experimentally characterized.

Recently, researches focus on designing UWB antenna with band rejection characteristics to eliminate any interference from narrowband wireless applications. This is achieved by adding slots with different shapes in the patch, feed and

Ground plane. In this paper the reference antenna design is provided in the in the section 1 . The proposed Antenna with Hexagonal patch is provided in the section 2. The measurement results for these antennas are provided in the section 3.Finally the paper is concluded in the section 4.With Acknowledgement and references respectively.

\section{Reference Antenna}

The reference rectangular micro strip patch antenna, shown in Fig. 1.To this antenna round steps are added at the upper and lower corners of the patch to get the pure resistive impedance circuit. The simulated RL results show better impedance matching and wider BW.

The simulated RL which is equal to -S11 (scattering parameter), for the reference antenna shows that with RL $\geq 10 \mathrm{~dB}$ the antenna has BW 3.42-11.7 GHz with minimum RL of $17 \mathrm{~dB}$.

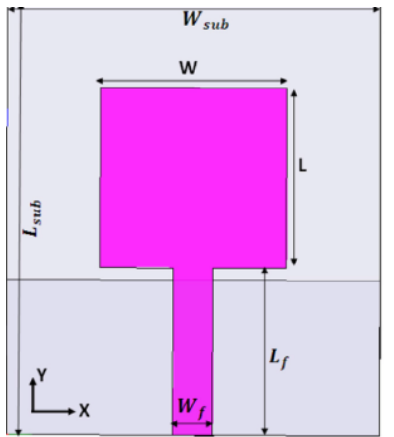

Fig 1 


\section{Band Rejection Using Slots}

Two rejected bands are achieved, the WLAN and X bands, by introducing slots in the antenna patch and the feed line.

Rejection of WLAN frequency band:

Four slot shapes (M, inverted-U, inverted-E and H) are inserted in the patch to reject the WLAN (5.15-5.825 $\mathrm{GHz}$ ) band. For the proposed antenna, we here use H-shape slot.

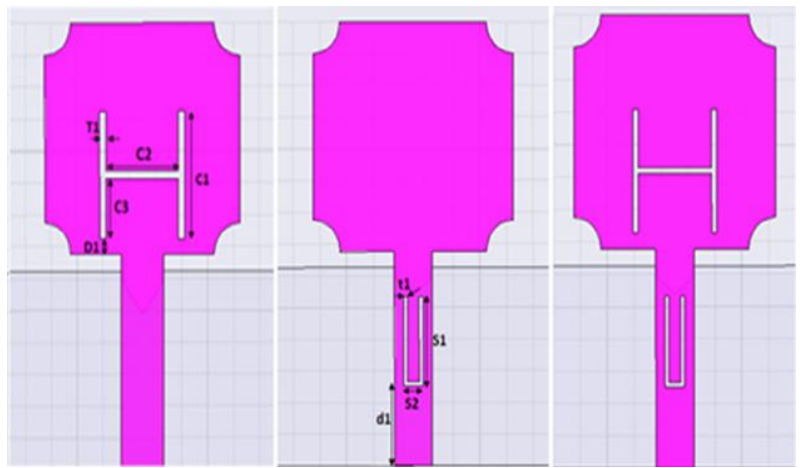

Fig2 (a) H-slot in the patch, (b) U-slot in the feed line and (c) Multi-slot H-U proposed antennas

Rejection of X-Band frequency range:

To reject the X-band downlink 7.25-7.75 GHz and uplink 7.9-8.4 GHz frequency ranges, slots are inserted in the micro strip feed line. The slot shape $U$ is used for the reference antenna as shown in Fig.2 (b)

Rejection of WLAN \& X-Band Frequencies:

In this type we combine the two slot types in the proposed antenna to form an antenna which rejects two bands as shown in Fig. 2(c). The simulated RL results for the H-U multi-slots antennas show that the rejection of the desired interferences from the WLAN and the X-band frequency ranges.

\section{Hexagonal micro strip Antenna}

\section{Proposed Antenna Design}

The Hexagonal micro strip antenna is shown in fig 3(a) is used for the better rejection of the bands and to get better return loss than the reference antenna. The simulated RL which is equal to -S11 (scattering parameter), shows that with $\mathrm{RL} \geq 10 \mathrm{~dB}$ the antenna has BW 3.42-11.7 GHz with minimum RL of $18.5 \mathrm{~dB}$.

Rejection of WLAN \& X-Band using slots:

Here also different slots are inserted into the patch and feed line as shown in the figure 3(b),3(c),3(d) of Hexagonal micro strip antenna to reject WLAN \& X-Band so as done for the proposed antenna design. The measurement results show better rejection of the bands and better return loss than the proposed antenna.

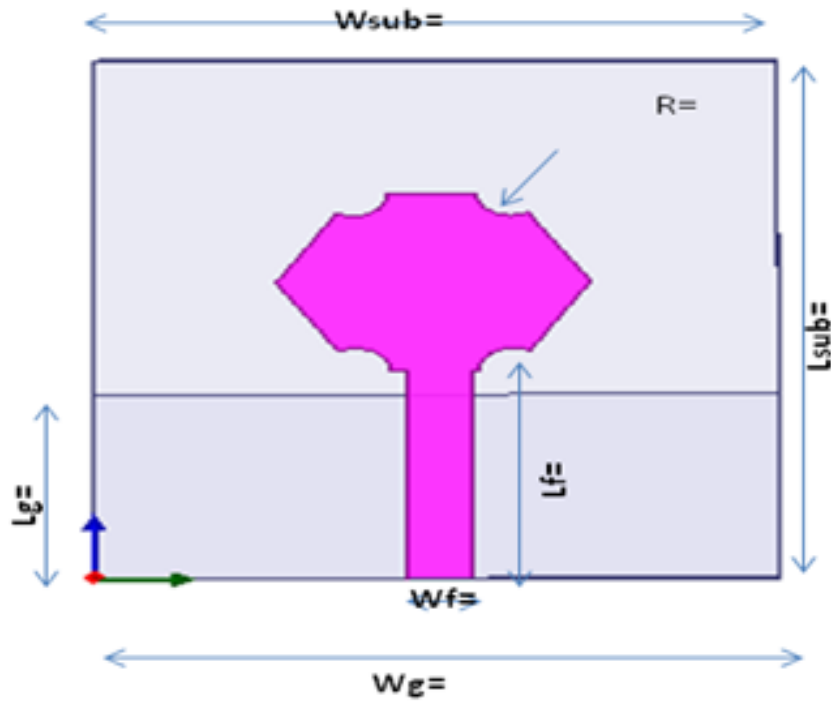

Fig 3(a) 

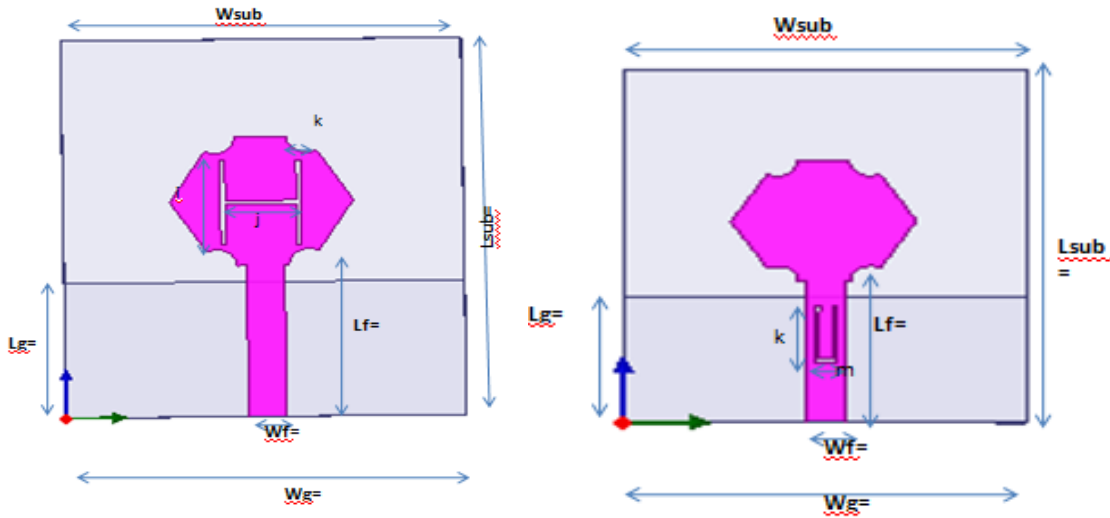

Fig 3(c)

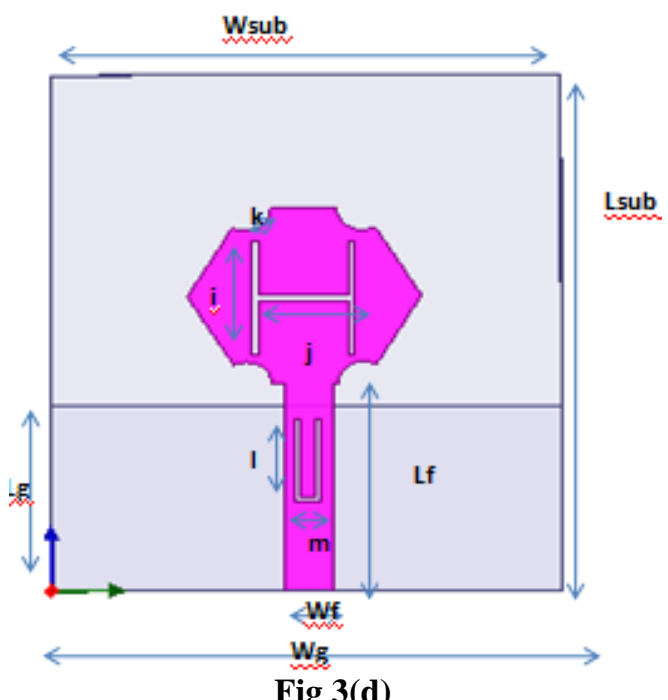

The Hexagonal micro strip patch antenna, shown in Fig.4 (a),4(b),4(c),4(d). The antenna dimensions (in $\mathrm{mm}$ ) are: the substrate has $\mathrm{Wsub}=30$, Lsub $=35$ and $\mathrm{h}=1.6$, the Hexagonal patch has width $\mathrm{W}=15$ and length $\mathrm{L}=14.5$, the feed line has $\mathrm{Wf}=2.85$ and $\mathrm{Lf}=14.05$, the partial ground plane has width $\mathrm{Wg}=30$ and length $\mathrm{Lg}=12.5, \mathrm{i}=5.63, \mathrm{k}=0.37, \mathrm{l}=5.63, \mathrm{~m}=0.311$ The simulated $\mathrm{RL}$ results show better impedance matching and wider $\mathrm{BW}$ than the reference antenna.

III. Results And Discussions

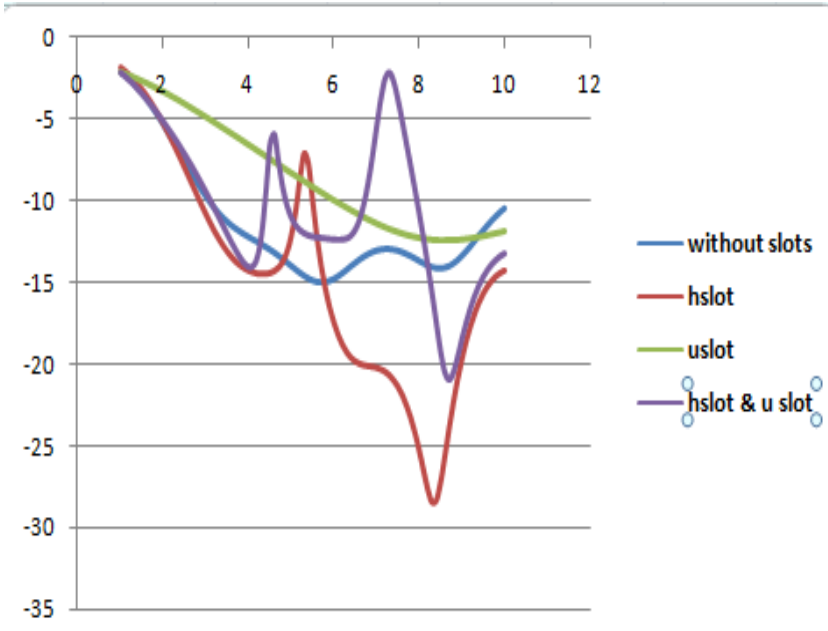

Fig 4 The simulated S11 curves for the Reference antenna without slots, with U-slot in feed only, with H-slot in the patch only and with multislots $\mathrm{H}-\mathrm{U}$. 


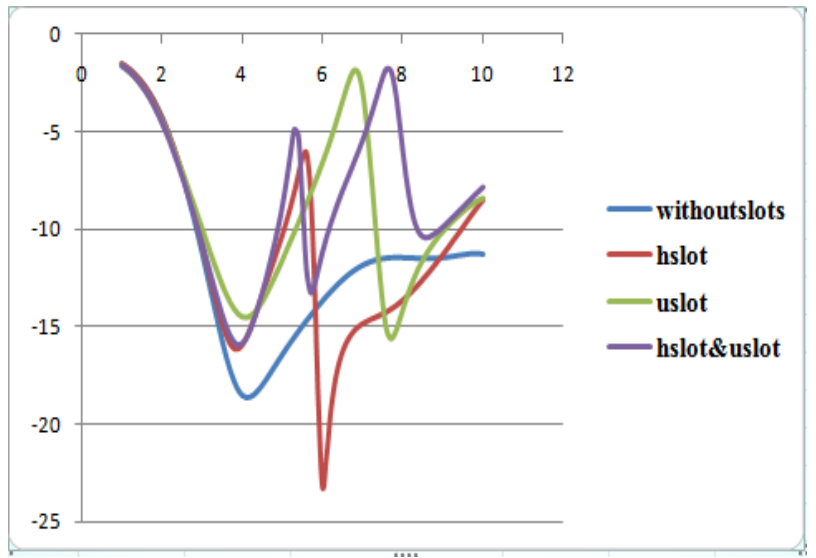

Fig 5 The simulated S11 curves for the proposed antenna without slots, with U-slot in feed only, with H-slot in the patch only and with multislots $\mathrm{H}-\mathrm{U}$.

Proposed Antenna Results

\begin{tabular}{|c|c|c|}
\hline type & Return loss (dB) & $\begin{array}{l}\text { Operating } \\
\text { frequency }(\mathrm{GHz})\end{array}$ \\
\hline Without slots & 18.5 & 4.2 \\
\hline With H-Slot & -22 & 6.1 \\
\hline With U-Slot & -14.5 & 7.8 \\
\hline $\begin{array}{c}\text { With both } \\
\text { H\&U-Slots }\end{array}$ & -16 & 4 \\
\hline
\end{tabular}
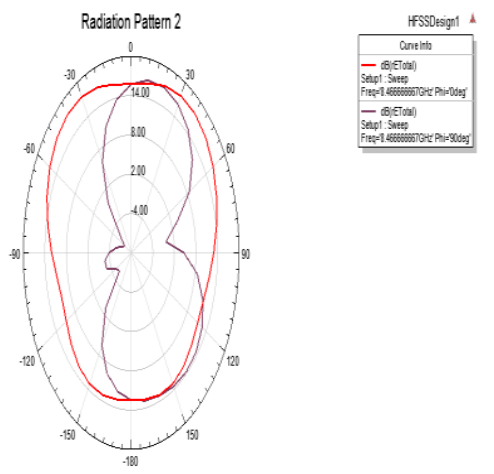

Fig 6 Reference antenna radiation pattern at operating frequency
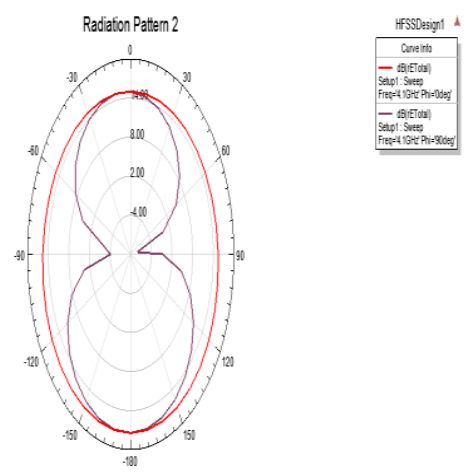

Fig7 Proposed antenna radiation pattern at operating frequency

\section{Conclusion}

Different multi-slot UWB antennas are7 designed to satisfy the requirements of the UWB systems and minimize the interferences from WLAN and X-band applications. The overall BW at RL $\geq 10 \mathrm{~dB}$ is $3.42-11.7$ $\mathrm{GHz}$ with better impedance matching. Slots are inserted in the patch and in the feed line to create rejection bands at WLAN and X-band frequency ranges respectively. Almost Omnidirectional radiation pattern is obtained in the H-plane and dipole shape in the E-plane is achieved with acceptable gain. 


\section{Acknowledgement}

We would like to express our thanks to N.RajSekhar (project guide) and technical staff for the support in the simulation process.

\section{References}

[1]. Ahmed, O., Abdel-Razik, A.S., 2009. A compact UWB butterfly shaped planar monopole antenna with bandstop characteristic. In: 13th International Symposium on Antenna Technology and Applied Electromagnetics and the Canadian Radio Sciences Meeting, Toronto, pp. 1-3.

[2]. Ali, J., Yassen, M., Hussan, M., Hasan, M., 2012. A new compact ultra wideband printed monopole antenna with reduced ground plane and band notch characterization. Progr. Electromagn. Res. Sympos. Proc. (PIERS), 1531-1536.

[3]. Chen, K.-R., Chow-Yen-Desmond, S., Jeen-sheen, R., 2011. A compact monopole antenna for super wideband applications. IEEE Antennas Wirel. Propag. Lett. 10, 488-491.

[4]. Choi, J., Kyungho, Ch., Yangwoon, R., 2005. Parametric analysis of a band rejection antenna for UWB application. Microwave Opt. Technol. Lett. 47 (3), 287-290.

[5]. Dargar, S.K., Bharti, S., Nyati, A., 2013 (Compact UWB antenna with T-shaped slots and staircase ground plane for enhanced bandwidth).IOSR J. Electron. Commun. Eng. (IOSR-JECE) 4, 12-17.

[6]. Eshtiaghi, R., Zaker, R., Nouronia, J., Ghobadi, Ch., 2010. UWB semi-elliptical printed monopole antenna with sub band rejection filter. Int. J. Electron. Commun. (AEU) 64 (2), 133-141.

[7]. FCC, 2002. Revision of Part 15 of the commission's rules regarding ultra wideband transmission systems, ET Docket 98-153, FCC $02-48$, February 14

[8]. Gupta, K., Garg, R., Bahl, I., Bhartia, P., 1996. Microstrip Lines and Slot lines, third ed. Artech House Antennas and Propagation Library, London.

[9]. Hu, Y.S., Li, M.,Gao, G.P., Zhang, J.S., Yang, M.K., 2010. A doubleprinted trapezoidal patch dipole antenna for UWB applications with band-notched characteristic. Progr. lectromagn. Res. (PIER) 103, 259-269. 